\title{
Action Taken in Managing Dental Health of Children due to Mother's Oral Health Literacy Level
}

\author{
Gilang R. Sabdho Wening, Karunia Nurensa, Taufan Bramantoro, Fidelia Kartikasari and Muhammad Faisal \\ Department of Dental Public Health, Faculty of Dental Medicine, Universitas Airlangga, Surabaya, Indonesia
}

\begin{abstract}
Background. The index of dental care needs of children from year to year tend to increase as shown in the results of the National Basic Health Research (Riskesdas). Children are individuals who still need the involvement of parents, especially mothers, in determining the attitudes and actions they will take to manage their dental health.
\end{abstract}

Methods. This study is a cross-sectional research in which a total of 108 women of childbearing age were randomly selected. An assessment was carried out on the actions taken by the mother in managing her child's dental health using the HU-DBI instrument (Hiroshima University Dental Behavioral Inventory), and Health Literacy in Dentistry (HeLD), to see the relationship with the level of dental health literacy they have.

Results. There was a significant difference in the aspect of understanding, in different decision making $(p=0.044)$ between the group of mothers who had a low HeLD score $(3.52 \pm 0.77)$ and the group of mothers who had a high HeLD score (3.70 \pm 0.46$)$.

Conclusion. The results showed that the aspects of understanding, ability to receive-treat-translate dental health information, and literacy level would lead to different actions in managing children's dental health.

Key Words: literacy, dental health, children, mother

\section{INTRODUCTION}

Paper presented at the Joint Scientific Meeting in Special Care Dentistry, July 5, 2019, Amerta Room, 4th Floor, main campus of Universitas Airlangga, Surabaya, Indonesia

Corresponding author: Gilang Rasuna Sabdho Wening Department of Dental Public Health

Faculty of Dental Medicine

Universitas Airlangga

Jl. Mayjen. Prof. Dr. Moestopo No. 47 Surabaya 60132 - Indonesia

Email: gilangrasuna@gmail.com
The high number of dental and oral diseases can be influenced by several factors. One of which is the behavior of the people who have not realized and understood the importantance of maintaining good dental and oral health. Oral Health Literacy (OHL) is a measure of a person's capacity and ability to obtain, process and understand basic dental and oral health information and health services needed to obtain appropriate health decisions. ${ }^{1}$ Oral health literacy can be used as an indicator in promoting dental and oral health, as well as preventing dental and oral health problems.

The ability of the Indonesian people to seek dental and oral health services is influenced by the high level of oral health literacy. Individuals with high level of health literacy have greater control over their community, so that they can improve and maintain their health. Meanwhile, individuals with low level of health literacy usually have low knowledge on health, health status, poor health behavior, and low utilization of preventive services. ${ }^{2}$

The first figure a child encounters in life is his mother. In a child's point of view, the mother is the figure who plays the most important role in the family. The interaction of children and parents, especially with mothers, is the main determinant in the development of a child's attitude. A child who is usually 
not so critical about something (preschool age) would have taken an attitude similar to that of his mother's behavior, a process of imitating the model he considers important. ${ }^{3}$

Preschool children experience the process of growth and development, both physically, mentally and socially. The process of growth and development is related to health conditions, one of which is dental and oral health. Children at this age have generally not sufficiently developed and are not mature enough to take care of their own teeth and mouth because at this age they do not think and make decisions on the health of their teeth and mouth. Therefore, in this case, parents are responsible, especially their mothers. The mother's participation is needed to guide, give attention to, remind, and provide the facilities for children to maintain the health and hygiene of children's teeth and mouth. ${ }^{4}$

The parent's knowledge on dental and oral hygiene is very important in the underlying formation of behavior of their children's dental and oral hygiene. A mother's behavior on dental and oral health may be used as an example by children so they can predict the status or condition of a child's teeth and mouth health. ${ }^{5}$ Therefore, it can be concluded that the mother's behavior on dental health determines the child's dental and oral health. In addition, there are studies that show OHL can affect the health status of the adult and child's oral cavity. ${ }^{6}$

In the context of dental and oral health, literacy includes things that are deeper than knowledge, where individuals can understand the causes of poor dental and oral health, learn and apply good dental and oral health behaviors, make appointments to come to the dentist's clinic, fill out the required health forms, make follow-up appointments, invite friends or family members to go to the dentist, and be able to comply on the use of prescription drugs. ${ }^{7}$ Based on this background, this study focused on the extent to which the role of maternal oral health literacy is able to influence the management of the oral health condition of preschool children.

\section{MATERIALS AND METHODS}

This study is a cross-sectional research model in which a total of 108 women of childbearing age were randomly selected. An assessment was carried out on the actions taken by the mother in managing her child's dental health using the HU-DBI instrument (Hiroshima University-Dental Behavioral Inventory), and Health Literacy in Dentistry (HeLD), to see the relationship with the level of dental health literacy they have. The sample criteria involved 3554 year old mothers of kindergarten children in Surabaya, able to read and write Indonesian and willing to participate in this research.

The instruments used in this study were the HeLD and the modified HU-DBI questionnaires. Both instruments were translated to the Indonesian language. HeLD was developed as a valid and culturally appropriate instrument for assessing oral health literacy. ${ }^{8}$ The questionnaire was analyzed based on seven domains, namely: Communication, Access, Receptivity, Understanding, Utilization, Support, and Economic Barrier. Communication domain is the ability of a person to communicate with a dentist to obtain information related to dental and oral health. There are 5 (five) question items in this domain. Access domain is someone's knowledge to get access to a dentist related to dental and oral health. It is assessed using three (3) question items. Receptivity domain is a person's ability to gather information related to dental and oral health. It is assessed with three (3) question items. Understanding domain is a person's ability to understand dental information so that he/she is able to fill out and answer the questionnaire. It is assessed using three (3) question items. Utilization domain is the ability of a person to carry out instructions given by the dentist to achieve the desired goal. This domain is assessed using the three (3) question items. Support domain is the ability of a person to get support from others to carry out activities related to dental and oral health, It is assessed using the three (3) question items. Economic Barrier is a domain which assess economic ability possessed by someone to meet needs related to dental and oral health. It is assessed using three (3) question items.

The seven domains measured showed an impact on oral health status. The results of these studies indicated that the HeLD instrument has a potential for use in a variety of health care settings. ${ }^{9}$ In addition, Jones in his study stated that oral health literacy measurements using this instrument can be used both in majority and minority groups. ${ }^{10}$ In this study, the HeLD questionnaire was used to measure the level of Oral Health Literacy of the mother, while the modified HU-DBI questionnaire was used to measure the actions taken by the mothers on a child's oral hygiene. The HeLD data was processed using the Difference Test in SPSS ${ }^{\mathrm{TM}}$ to find the difference of mother's actions taken in managing their children's oral health based on her oral health literacy.

\section{RESULTS}

This research was carried out in six (6) randomly selected kindergartens (TK) in Surabaya with a total of 108 biological mothers The study was conducted in August and September 2017. The data collected were recapitalized so that data obtained were in the form of respondent characteristics and the relationship between oral health literacy level with the actions taken by the mother in managing the health of the teeth and mouth of their children (Table 1).

To measure the level of Oral Health Literacy, the Health Literacy in Dentistry (HeLD) questionnaire was used. The HeLD questionnaire consisted of 29 questions divided into the 7 domains, namely, receptivity, understanding, support, economy, access, communication, and utilization.

Each question has an answer that is scored using the 5 -point Likert scale which is used to allow the individual to express how much they agree or disagree with a particular 
Mother's Oral Health Literacy Level and Children's Dental Health Management

Table 1. Relationship between maternal literacy variables (mean HELD) and the quality of actions taken by mothers (HUDBI items) on their children's dental health status

\begin{tabular}{|c|c|c|c|c|c|c|c|c|c|}
\hline \multirow{2}{*}{ VAR } & \multirow{2}{*}{$\mathbf{N}(\%)$} & \multirow{2}{*}{$\begin{array}{l}\text { Mean } \\
\text { HeLD }\end{array}$} & \multicolumn{7}{|c|}{ Mean HeLD Domain } \\
\hline & & & Receptivity & Understanding & Support & Economy & Access & Communication & Utilisation \\
\hline \multicolumn{10}{|l|}{ HUDBI Action } \\
\hline High & $38(35)$ & $3.30 \pm 0.64$ & $3.31 \pm 0.81$ & $3.70 \pm 0.46$ & $2.88 \pm 1.02$ & $3.29 \pm 0.82$ & $3.07 \pm 1.25$ & $3.33 \pm 0.74$ & $3.44 \pm 0.67$ \\
\hline Low & $70(65)$ & $3.22 \pm 0.60$ & $3.42 \pm 0.74$ & $3.52 \pm 0.77$ & $2.86 \pm 0.95$ & $3.16 \pm 0.86$ & $2.98 \pm 1.09$ & $3.19 \pm 0.78$ & $3.32 \pm 0.69$ \\
\hline$p$ value & & 0.414 & 0.180 & $0.044^{*}$ & 0.545 & 0.926 & 0.422 & 0.514 & 0.862 \\
\hline \multicolumn{10}{|l|}{ Educational Level } \\
\hline Elementary Education & 69 (63.90) & $3.15 \pm 0.65$ & $3.33 \pm 0.85$ & $3.55 \pm 0.67$ & $2.82 \pm 1.00$ & $3.10 \pm 0.80$ & $2.78 \pm 1.19$ & $3.13 \pm 0.83$ & $3.27 \pm 0.75$ \\
\hline Higher Education & 39 (36.10) & $3.43 \pm 0.49$ & $3.49 \pm 0.58$ & $3.66 \pm 0.71$ & $2.96 \pm 0.91$ & $3.39 \pm 0.89$ & $3.42 \pm 0.95$ & $3.45 \pm 0.59$ & $3.54 \pm 0.51$ \\
\hline$p$ value & & $0.048^{*}$ & 0.395 & 0.523 & 0.672 & 0.170 & $0.019^{*}$ & 0.070 & 0.051 \\
\hline
\end{tabular}

statement. The total score of each respondent is averaged from the score of each question. The highest value is 4 and the lowest value is 0 . Based on Table 1 , the mean score HeLD in Uncategorized respondents with a high response action against the child's dental problems (35\% of total respondents) was 3.30 with a standard deviation of 0.64 . The categorized respondents on the other hand has a low response to a child's dental problems $(65 \%$ of the total respondents) has a lower average HELD score of 3.22 with a standard deviation of 0.60. Meanwhile, on the aspects of the HELD domain, from 7 domains, which have meaningful differences are the aspects in the domain of Understanding. In this aspect, the understanding of mothers with a high response to their children's dental health problems had a significantly higher score compared to the group of mothers who had a low response to their children's dental health problems $(p=0.044)$.

Knowledge of oral health, oral health behavior, and selfefficacy are important components in the oral health literacy framework. Self-efficacy is the belief in a person's ability to regulate and implement the actions needed to manage a prospective situation. ${ }^{11}$ One of the important things for this framework is education, which is the main determinant in the prevalence and severity of dental and oral diseases. At different levels of education, the ability of individuals is trained. At the initial education level, the ability to read and write is trained. This capability will be the basis for more complex abilities such as understanding and applying, which will be trained at a higher level of education. ${ }^{12}$

Generally, there is a comparable relationship between the individual's educational level and oral health outcomes that may be directly related to the quality of life. A high level of education allows one to obtain and understand information about oral health behavior and oral health promotion. ${ }^{13}$

Based on Table 1, respondents who graduated from college had a higher average HELD score compared to respondents who only had the opportunity to complete basic education. A deeper review on the aspect of Access $(p=0.019)$ in the HELD domain showed a significant difference between the two respondent groups based on their education.

\section{DISCUSSION}

The role of parents is necessary in the maintenance of children's dental health. The pattern of healthy behavior of parents in general will have an impact on the level of children's health including dental and oral health. The behavior in maintaining health by parents is very important in the underlying formation of their behavior to support or not support the dental and oral hygiene of children. Parents' behavior on dental and oral health problems can be an example to their children, so it is important to pay attention to the maternal oral and dental health behavior because it is useful in preventing children's dental and oral health problems. ${ }^{12}$

To determine the extent to which a person's dental and oral health behavior, it needs a measurement instrument. In this study, the Hiroshima University - Dental Behavioral Inventory (HU-DBI) questionnaire was used to measure the behavior of mothers in caring for and accustoming their children to maintaining dental and oral health. Whereas in reviewing and analyzing the basic behavior of mothers, Oral Health Literacy (OHL) was used. Oral Health Literacy (OHL) is a degree of ability a person has to obtain, process, and understand basic dental health information and health services needed to get appropriate health decisions. OHL can be used to promote dental and oral health so that it can prevent dental and oral health problems. To increase the OHL level, it is necessary to pay attention to the behavior of each individual to maintain dental and oral health and several other related factors. This is supported by research conducted by Ueno, that there is a significant relationship between OHL levels and the behavior of maintaining oral health. ${ }^{13}$

The Health Literacy in Dentistry score was used as a benchmark for whether a person (in this case, mother) has a good foundation of literacy in behaving and managing the dental health of her child. The average HeLD score on categorized respondents had a high response to their children's dental problems (35\% of the total respondents) and higher HELD score when compared with categorized respondents who had a low response to their children's 
dental problems (65\% of total respondents). Benjamin Bloom ${ }^{14}$ states that human behavior can be determined by aspects of knowledge, attitude, and action. Knowledge aspect is the most important aspect as the basis for forming a behavior. Knowledge is the result or manifestation of sensing a particular object. In the OHL concept, the degree of assessment of the level of literacy is dominated by the wealth of knowledge possessed by the respondent, so if you look at the findings that the respondent with a high HELD score, there will be a high response to the child. In this study, what is meant by high actions in managing the dental health of their children is in the form of: Knowing there are white spots on a child's teeth; Do not hesitate to visit the dentist to check the child's oral health; Children have been taught how to brush their teeth properly; Children brush their teeth using a size toothbrush for children; Requires enough time to clean the child's teeth; Brushing each child's teeth carefully until clean; Frequently checking children's teeth in the glass after brushing; Checking children's teeth to the dentist instead of just when it hurts; and Using a colored material to see the children's dental hygiene.

Education is one of the important determinants of a person in behaving to decide on health services, so that it becomes one of the main points that must be considered further. In addition, Atchison states that there is a correlation between education and OHL levels, where there is an increase in the average OHL questionnaire (REALM-D) followed by an increase in the education level of respondents. ${ }^{15}$ Meanwhile, respondents with low levels of education tended to have a more critical level of health literacy. This is consistent with the results of the study that mothers who graduated from higher education had a higher average OHL level compared to mothers who only completed basic education. Specifying the different aspects of domain "access". It is known that in HELD instruments, the aspect of domain "access" is someone's knowledge to gain access to dentists related to dental and oral health. In this study, respondents with high educational backgrounds had better determinants in deciding to access dental and oral health services for their children.

\section{CONCLUSION}

The results of this study can provide an overview of the relationship between the level of oral health literacy and maternal behavior in managing the dental and oral health of preschoolers. In this study, the literacy aspect in the form of a mother's understanding of children's dental and oral health is dominant in creating the differences in decision making. Therefore, it is important to educate and/or provide comprehensive information to mothers on the importance of maintaining the health of the children's teeth and mouth. If done, it will be able to support the mother's attitude which will lead to a mother to act in managing the health of her children's teeth and mouth.

\section{Statement of Authorship}

All authors participated in data collection and analysis, and approved the final version submitted.

\section{Author Disclosure}

All authors declared no conflict of interest.

\section{Funding Source}

None.

\section{REFERENCES}

1. Ueno M, Takeuchi S, Oshiro A, Kawaguchi Y. Relationship between oral health literacy and oral health behaviors and clinical status in Japanese adults. J Dent Sci. 2013; 8(2):170-176. https://doi. org/10.1016/j.jds.2012.09.012

2. Lee JY, Divaris K, Baker AD, Rozier RG, Vann WF Jr. The relationship of oral health literacy and self-efficacy with oral health status and dental neglect. Am J Public Health. 2012; 102(5):923-9. doi: 10.2105/ AJPH.2011.300291.

3. Azwar S. Human Attitudes Theory and Measurement. Yogyakarta: Student Library. 1997.

4. Moghadam MHB, Azad MM, Biria M, Sabour S. Evaluation of oral hygiene care of under 4 years old children by their mothers based on the Health Belief Model. Journal of Dental School 2015; 33(1):9-18.

5. The Soeparmin S. Pedodontic treatment triangle plays a role in the process of successful child dental care. JKGUNMAS. 2012: 1-39.

6. Budiharto. Age, education, number of children, family economic status, use of dental health facilities and dental health education on mother behavior. JKGUI; 1998:5 (2):99-108.

7. Budiharto. Introduction to Health Behavior Sciences and Dental Health Education. Jakarta: EGC; 2010.

8. Lee JY, Divaris K, Baker AD, Rozier RG, Lee SYD, Vann WF Jr. Oral health literacy levels among a low-income WIC population. J Public Health Dent. 2011; 71(2):152-160.

9. Parker EJ, Jamieson LM., Associations between Indigenous Australian oral health literacy and self-reported health outcomes. BMC Oral Health 2010; 10:3. doi: 10.1186/1472-6831-10-3.

10. Rahardjo A, Adinda S, Nasia AA, Adiatman M, Setiawati F, Wimardhani YS, et al. Oral Health Literacy in Indonesian Adolescent. J Int Dent Med Res. 2015; 8(3):123-7.

11. Jones K, Parker E, Mills H, Brennan D, Jamieson LM. Development and psychometric validation of a Health Literacy in Dentistry scale (HeLD). Community Dent Health. 2014; 31(1):37-43.

12. Bandura A. Self-efficacy. In: VS Ramachaudran, ed. Encyclopedia of human behavior. New York: Academic Press; 1994. pp. 71-81.

13. Nielsen-Bohlman L, Panzer A, Kinding D., Health literacy. Washington DC: National Academies Press. 2004

14. Krathwohl DR, Bloom BS, Masia BB. Taxonomy of educational objectives: The classification of educational goals. Handbook II: the affective domain. New York: David McKay Company; 1964.

15. Timis T, Danila I. Socioeconomic status and oral health. Journal of Preventive Medicine. 2005; 13(1-2):116-21. 